\title{
Resistance/response molecular signature for oral tongue squamous cell carcinoma
}

\author{
Amritha Suresh $^{\mathrm{a}}$, Muhil Vannan ${ }^{\mathrm{b}, 1}$, Dhanya Kumaran ${ }^{\mathrm{b}, 2}$, Zeynep H. Gümüs ${ }^{\mathrm{c}}$, Priya Sivadas ${ }^{\mathrm{a}}$, \\ Elango Erode Murugaian ${ }^{\mathrm{d}}$, Vikram Kekatpure $^{\mathrm{a}}$, Subramanian Iyer $^{\mathrm{b}}$, Kumarasamy Thangaraj ${ }^{\mathrm{e}}$ and \\ Moni Abraham Kuriakose ${ }^{\mathrm{a}, *}$ \\ ${ }^{a}$ Head and Neck Oncology Services, Mazumdar Shaw Cancer Centre, Narayana Hrudayalaya Foundations, \\ Bangalore, India \\ ${ }^{\mathrm{b}}$ Head and Neck Surgery, Amrita Institute of Medical Sciences and Research Centre, Kochi, India \\ ${ }^{\mathrm{c}}$ Department of Physiology and Biophysics and HRH Prince Alwaleed Bin Talal Bin Abdulaziz Alsaud Institute for \\ Computational Biomedicine, Weill Medical College of Cornell University, New York, NY, USA \\ ${ }^{\mathrm{d}}$ Department of Molecular Diagnostics, Mazumdar Shaw Cancer Centre, Narayana Hrudayalaya Foundations, \\ Bangalore, India \\ ${ }^{\mathrm{e}}$ Centre for Cellular and Molecular Biology, Hyderabad, India
}

\begin{abstract}
Worldwide, the incidence of oral tongue cancer is on the rise, adding to the existing burden due to prevailing low survival and high recurrence rates. This study uses high-throughput expression profiling to identify candidate markers of resistance/response in patients with oral tongue cancer. Analysis of primary and post-treatment samples (12 tumor and 8 normal) by the Affymetrix platform (HG U133 plus 2) identified 119 genes as differentially regulated in recurrent tumors. The study groups had distinct profiles, with induction of immune response and apoptotic pathways in the non-recurrent and metastatic/invasiveness pathways in the recurrent group. Validation was carried out in tissues by Quantitative Real-Time PCR (QPCR) $(n=30)$ and immunohistochemistry (IHC) $(n=35)$ and in saliva by QPCR $(n=37)$. The markers, COL5A1, HBB, IGLA and CTSC individually and $C O L 5 A 1$ and $H B B$ in combination had the best predictive power for treatment response in the patients. A subset of markers identified (COL5A1, ABCG1, MMP1, IL8, FN1) could be detected in the saliva of patients with oral cancers with their combined sensitivity and specificity being 0.65 and 0.87 respectively. The study thus emphasizes the extreme prognostic value of exploring markers of treatment resistance that are expressed in both tissue and saliva.
\end{abstract}

Keywords: Tongue cancer, resistance, response, micro array, gene expression, saliva, biomarkers

\section{Introduction}

Among various sub-sites of oral cancer, carcinoma of the tongue poses a grave health concern. The inci-

\footnotetext{
${ }^{1}$ Present Address: Environmental Health Division, National Environmental Engineering Research Institute, Nagpur, 440020, India.

${ }^{2}$ Present Address: Prof. Gaiti Hasan's Lab, National Centre for Biological Sciences, Tata Institute of Fundamental Research, Bangalore, 560065, India.

* Corresponding author: Dr. Moni A Kuriakose MD FRCS, Professor and Director, Surgical Oncology, Chief, Head and Neck Oncology, Mazumdar Shaw Cancer Centre, Narayana Hrudayalaya, Bommasandra Indl Area, Anekal Taluk, Bangalore, 560099 India. Tel.: +91 080 22142229; Fax: +91 080 22142228; E-mail: mak12@nyu. edu.
}

dence rate of tongue carcinoma is on the rise, up to 8 per annum per 100,000 [1]. There is also a higher locoregional failure rate as compared to other oral cavity sub-sites [2,3]. High-throughput genomic, transcriptomic and proteomic studies provide an opportunity to evaluate a large number of novel molecular markers with prognostic significance [4,5]. It would be advantageous if these biomarkers can be isolated in accessible body fluids, in order to attain wider clinical utility. Saliva is currently emerging as a promising, non-invasive means for detection of molecular indicators of disease conditions [6,7]. In this context, studies reporting differential patterns of transcriptome and proteome in saliva from normal controls and oral cancer patients [8-11] and between premalignant and malignant lesions [12] 
gain significance. The molecular markers identified by global expression studies, if detected and validated in the saliva of oral cancer patients, would establish an easy means of prognosis and can hence, further their use in clinical application.

This study primarily aims to establish a molecular signature specific to resistance and/or response to standard treatment for oral tongue squamous cell carcinoma. As a secondary objective, a subset of the biomarkers was further tested in saliva of oral cancer patients to determine their efficacy in diagnosis and prognosis.

\section{Patients and methods}

\subsection{Patient details and sample collection}

The tissue samples were collected from patients undergoing surgical treatment after obtaining Institutional Review Board approval and written informed consent. The samples subjected to microarray analysis were collected in RNA later (Ambion, Austin, USA), while the samples for validation were either snap frozen or collected in RNA later and archived at $-80^{\circ} \mathrm{C}$. The clinical characteristics of the patients were obtained from the electronic medical records maintained at the tertiary care cancer center. The sample sets were grouped into three categories: Group I (Pre-treatment, non-recurrent), which included pre-treatment tissues from patients who remained disease-free after standard treatment (surgery and adjuvant chemo radiation); Group II (Pre-treatment resistant/recurrent) included pre-treatment tissues from those who recurred during a 2-year follow up period; Group III (post-treatment recurrent; standard treatment) included recurrent tissue from patients with the recurrent disease. Group I \& III were analyzed by micro array, while the validation was carried out in all the three groups. The adjacent mucosal tissue was collected $2 \mathrm{~cm}$ away from the tumor and confirmed as histologically negative for malignancy. Normal oral mucosa was also collected from non-diseased controls (age and risk factor matched) after written informed consent. Saliva samples were collected from healthy volunteers and previously untreated patients diagnosed with oral cancer (Stage I/II), after informed written consent. Unstimulated saliva was collected and mixed with RNAlater (Ambion, Austin USA) and stored at $-80^{\circ} \mathrm{C}$.

\subsection{RNA isolation, labeling of $c R N A$ and hybridization}

Total RNA was isolated using the Qiagen RNeasy Kit (Qiagen, CA, US) and the samples that qualified through standard quality control criteria were selected for microarray. 100-200 ng of RNA was taken and biotinylated cRNA was prepared using the Twocycle labeling Kit protocol (Affymetrix, CA, USA). The labeled cRNA was purified by the Genechip sample cleanup module (Qiagen, CA, US), fragmented and $20 \mu \mathrm{g}$ hybridized to HGU133 plus 2 arrays $(54,675$ probes) using standard Affymetrix protocols. The hybridized chips were washed, stained and scanned by the Affymetrix Fluidics Station and Genechip Scanner 3000 using prescribed protocols.

\subsection{Microarray analysis}

The preliminary analysis to ascertain the internal controls and the hybridization efficiency was carried out using the Gene Chip Operating Software (GCOS) and Microarray Suite (MAS 5, Affymetrix, CA, USA). The CEL files were extracted and imported into GeneSpring 7.2 (Agilent Technologies, CA, USA) software package for analysis. Raw image data were background corrected, normalized and summarized into probe set expression values using Robust Microarray Analysis (RMA) algorithm [13]. For inter-array comparisons, data from each chip was normalized to $50 \%$ of the measurements taken from that chip (measurements of $<$ 0.01 were set to 0.01 ). Probe sets that were not reliably detected were removed, by filtering out those whose expression level was not $>50$ and confidence $p$-values $<$ 0.05 , in at least $20 \%$ of the samples. To identify genes differentially expressed, both in the non-recurrent and recurrent tongue cancers as compared to adjacent mucosal samples, the remaining genes were subjected to Welch's $t$-test, not assuming variances equal, at $p<$ 0.05 and furthered filtered for fold change $>1.5$. A subset of genes, identified by the analysis, was selected for further validation.

Ingenuity Pathway Analysis was carried out to identify significant functions, signaling pathways and networks (Ingenuity Systems Inc. CA, USA) at the default core analysis and core comparison platforms. Fishers' exact test was used to identify the statistically significant functions/pathways. The differentially expressed genes were hierarchically clustered using Multi Experiment Viewer, $v 4.5(\mathrm{MeV})$ (TM4 Microarray Software Suite, The Institute of Genomic Research (TIGR)) [14] 
Table 1

Primers used for quantitative PCR

\begin{tabular}{|c|c|c|c|}
\hline S No & Gene & Primer sequence $\left(5^{\prime}-3^{\prime}\right)$ & Amplicon size (bp) \\
\hline 1 & MMP1 & $\begin{array}{l}\text { F: ACACATGGTGTGAGTCC } \\
\text { R: TGGCCTATATGAATCCATAAGC }\end{array}$ & 226 \\
\hline 2 & EMP1 & $\begin{array}{l}\text { F: TGGGGAGTTGTTATGCC } \\
\text { R: GCACTAAGACAGCCTTCT }\end{array}$ & 214 \\
\hline 3 & ABCG1 & $\begin{array}{l}\text { F: CAGGAAGATTAGACACTGTGG } \\
\text { R: GAAAGGGGAATGGAGAGAAGA }\end{array}$ & 177 \\
\hline 4 & COL5A1 & $\begin{array}{l}\text { F:CACAACTTGCCTGATGGAATAACA } \\
\text { R: GCAGGGTACAGCTGCTTGGT }\end{array}$ & 134 \\
\hline 5 & IGLA & $\begin{array}{l}\text { F: GAGCCTGACGCCTGAGCA } \\
\text { R: AGGGAGAAGGGCTTGATGC }\end{array}$ & 203 \\
\hline 6 & HBB & $\begin{array}{l}\text { F: GTGCATCTGACTCCTGAG } \\
\text { R: CCCAAAGGACTCAAAGAAC }\end{array}$ & 138 \\
\hline 7 & CTSC & $\begin{array}{l}\text { F: CCTATCTTGACCTGCTGG } \\
\text { R: GCCAGAATTGCCAAGGTC }\end{array}$ & 155 \\
\hline 8 & CCL18 & $\begin{array}{l}\text { F: CTGCCTCGTCTATACCTC } \\
\text { R: CACTTCTTATTGGGGTCAG }\end{array}$ & 141 \\
\hline 9 & FN1 & $\begin{array}{l}\text { F: CAGACCCAGCTTAGAGT } \\
\text { R: CATCTTGGTTGGCTGC }\end{array}$ & 247 \\
\hline 10 & FAPA & $\begin{array}{l}\text { F: ATGCAAGCCTGTATCAGA } \\
\text { R: ACACTGTGTCCAAAGC }\end{array}$ & 231 \\
\hline 11 & SERPINH2 & $\begin{array}{l}\text { F: CCTGGGCCATAGTCATT } \\
\text { R: GGTGTTTTAGTGTCAGAAGAG }\end{array}$ & 148 \\
\hline 12 & IL8 & $\begin{array}{l}\text { F: GAGGGTTGTGGAGAAGTTTTTG } \\
\text { R: CTGGCATCTTCACTGATTCTTG }\end{array}$ & 88 \\
\hline 13 & IL1B & $\begin{array}{l}\text { F: GTGCTGAATGTGGACTCAATCC } \\
\text { R: ACCCTAAGGCAGGCAGTTG }\end{array}$ & 120 \\
\hline 14 & GAPDH & $\begin{array}{l}\text { F: TCACCAGGGCTGCTTTTAACTC } \\
\text { R: ATGACAAGCTTCCCGTTCTCAG }\end{array}$ & 150 \\
\hline
\end{tabular}

with the Euclidean distance measurement and $p$ values were calculated after application of the non-parametric Wilcoxon-Mann Whitney test $(p<0.5)$. Furthermore, $K$-means clustering $(\mathrm{K}=10$; Euclidean distance) was carried out to identify a sub-set of genes that would clearly differentiate the groups under study.

\subsection{Validation of the microarray data in tissue and saliva samples by Quantitative PCR}

RNA was isolated from tissues using Tri Reagent (Sigma Aldrich, MO, USA), first strand synthesis was done using $M M L V$ Reverse transcriptase (Ambion, Austin, USA) and Quantitative Real Time PCR (QRT PCR) by the Power Syber Green kit (Applied Biosystems, CA, USA) in an ABI 7300 Cycler (Applied Biosystems, CA, USA). The expression levels of the genes selected for validation (MMP1, EMP1, ABCG1, COL5A1, IgLA, HBB, CTSC and CCL18) (Table 1) was assessed by QRT PCR using the relative quantification $(\Delta \Delta \mathrm{CT})$ method [15]. Expression was normalized using the endogenous control $(G A P D H)$ and normal oral mucosal tissues were used as the calibrator. Melting curve analysis was done to ensure the specificity of the product obtained.
Unstimulated saliva collected from patients/controls was mixed with RNAlater; subsequently the samples were centrifuged at $14,000 \mathrm{rpm}$ for 20 minutes at $4^{\circ} \mathrm{C}$. RNA was isolated from the salivary supernatant using the Qiagen Viral RNA Kit (Qiagen, CA, US). The samples were assessed for their integrity using the expression of the endogenous control (GAPDH) by Reverse Transcription PCR (RT-PCR) as a criterion. A subset of 10 candidate markers (MMP1, FN1, FAPA, SERPINH2, IL8, IL1B, IgLA, ABCG1, COL5A1,HBB), selected from this study and a previous microarray study [16], were tested for their expression in saliva by QRT PCR. The fold levels of expression were calculated using the $\triangle \triangle \mathrm{CT}$ method, with the GAPDH expression used as the endogenous reference and the saliva samples from healthy volunteers as the calibrator. The detection of one or more markers in the samples was considered as 'test positive $=1$ ' while absence of any of the markers was considered 'test negative $=0$ '. The combined test result in the binary input format was used for the statistical analysis. The expression patterns were correlated to the disease status of the patients to ascertain their clinical relevance. 
Table 2

Clinical characteristics of patients

\begin{tabular}{|c|c|c|c|c|c|c|}
\hline \multirow[t]{2}{*}{ Study } & \multirow{2}{*}{$\begin{array}{c}\text { Sample } \\
\text { size }\end{array}$} & \multirow{2}{*}{$\begin{array}{c}\text { Med } \\
\text { age } \\
\text { (Years) }\end{array}$} & \multicolumn{2}{|c|}{ Risk habits\# } & \multirow{2}{*}{$\begin{array}{c}\text { Med } \\
\text { follow up } \\
\text { (months) }\end{array}$} & \multirow{2}{*}{$\begin{array}{r}\text { Med DFS } \\
\text { (months) }\end{array}$} \\
\hline & & & $\begin{array}{l}\text { With } \\
\text { Risk }\end{array}$ & $\begin{array}{c}\text { Without } \\
\text { Risk }\end{array}$ & & \\
\hline Microarray Set & 12 & 54.5 & 6 & 6 & 47 & \\
\hline \multicolumn{7}{|l|}{ Study Groups } \\
\hline Group I & $6 \mathrm{~T}, 4 \mathrm{~N} *$ & 43 & 3 & 3 & 48 & - \\
\hline Group III & $6 \mathrm{~T}, 4 \mathrm{~N}$ & 58 & 3 & 3 & 46 & 5.5 \\
\hline Validation Set & 65 & 55.5 & 31 & 22 & 23.5 & \\
\hline \multicolumn{7}{|l|}{ Study Groups } \\
\hline Group I & 34 & 60 & 19 & 9 & 27 & \\
\hline Group II & 19 & 56 & 6 & 10 & 23.5 & 12 \\
\hline Group III & 12 & 48 & 6 & 3 & 20.5 & 4 \\
\hline QRT & 30 & 57 & 14 & 9 & 23 & \\
\hline Group I & 14 & 58 & 7 & 3 & 22 & - \\
\hline Group II & 8 & 58 & 3 & 4 & 23 & 11 \\
\hline Group III & 8 & 50 & 4 & 2 & 21.5 & 3.5 \\
\hline $\mathrm{IHC}$ & 35 & 56 & 20 & 13 & 30 & \\
\hline Group I & 20 & 60 & 13 & 6 & 35 & - \\
\hline Group II & 11 & 49 & 4 & 6 & 28 & 16.5 \\
\hline Group III & 4 & 48 & 3 & 1 & 16.5 & 13 \\
\hline Saliva & 37 & 51 & 11 & 14 & & \\
\hline Normal & 12 & 52 & 4 & 6 & - & \\
\hline $\mathrm{T} 1 / \mathrm{T} 2$ & 25 & 50 & 7 & 8 & 18 & \\
\hline
\end{tabular}

* T: Tumor; N: Normal.

\# Risk factor details provided for patients wherever information is available.

\subsection{Immunohistochemical analysis}

The protein expression of two genes (COL5A1 and $H B B)$, validated by QRT PCR was profiled in the tissue sections of a different cohort of patients with tongue cancer. The sections were deparaffinized and IHC carried out according to standard protocols. The antibodies were used in dilutions of 1:50 for both COL5A1 (sc133162; Santacruz Biotechnology, Santacruz, CA, USA) and HBB (H4890; Sigma Aldrich,USA). The sections were microwaved for antigen retrieval and the staining detected by Dako REAL ${ }^{\mathrm{TM}}$ EnVision $^{\mathrm{TM}}$ kit (Dako Corporation, Carpenteria, CA, USA). The sections were counterstained using haematoxylin and scanned at low and high power to identify areas of even staining and percentage of positive cells. The grades of positivity were scored as follows; negative $(<1 \%)$, grade I (1-10\%), grade II (10-30\%), III (30-60\%) and IV $(>60 \%)$. The intensity of staining was also graded as mild, moderate and intense. The expression in the normal oral mucosal tissues was used as control.

Receiver Operating Characteristic (ROC) curve analyses were carried out by SPSS 19 (IBM) and MedCalc ${ }^{\circledR}$ $v$ 11.6.0.0 for the QPCR and IHC results. Area under the curve was computed via numerical integration of the ROC curves. The biomarkers, individually or in combination, with the largest Area under Curve (AUC) were identified to have the maximum predictive pow- er for disease recurrence. Multiple regression analysis was also carried out by the stepwise method to identify the predictive value of the marker combinations.

\section{Results}

\subsection{Patient characteristics}

The microarray study included 20 tissue samples collected from 12 patients, the study groups each included 6 tumor and 4 adjacent normal samples from patients of Group I (Pre-treatment, non-recurrent) [median follow up: 48 months (range 26-49 months)] and from Group III (post-treatment, recurrent) respectively. The median age of the patients was 54.5 years (range 35-66); 10 patients were male and 2 were female. The detailed characteristics of the patients are given in the Table 2 .

The validation set included 65 patients diagnosed with oral tongue cancer with a median follow up of 23.5 months (range 11-49 months). Thirty patients were validated by QPCR (median follow up: 23 months, range: 11-42); 14 classified as Group I (Pre-treatment non-recurrent), 8 as Group II (Pretreatment resistant/recurrent) (median DFS: 11 months) and 8 as Group III (post-treatment recurrent) (median DFS: 3.5 months; range 2-7 months). Among the 35 patients analyzed by IHC (median follow up: 
Table 3

Subset of the significant genes obtained in Non-recurrent and Recurrent

\begin{tabular}{|c|c|c|c|c|c|c|}
\hline \multicolumn{7}{|c|}{ Non recurrent $\mathrm{T}$ vs $\mathrm{N}$} \\
\hline $\begin{array}{c}\text { Sl } \\
\text { No }\end{array}$ & $\begin{array}{l}\text { Affymetrix } \\
\text { ID }\end{array}$ & $\begin{array}{l}\text { Gene } \\
\text { symbol }\end{array}$ & $\begin{array}{c}\text { Fold } \\
(\text { NR/Normal) }\end{array}$ & $\begin{array}{c}\mathrm{p} \\
(\mathrm{NR} / \mathrm{Normal})\end{array}$ & $\begin{array}{c}\text { Fold } \\
\text { (R/Normal) }\end{array}$ & $\begin{array}{c}\mathrm{p} \\
\text { (R/Normal) }\end{array}$ \\
\hline 1 & 204475_at & MMP1 & 255.50 & 0.00012 & 74.50 & 0.00519 \\
\hline 2 & 213139_at & SNAI2 & 5.81 & 0.00014 & 2.81 & 0.0222 \\
\hline 3 & 202458_at & PRSS23 & 8.77 & 0.000186 & 4.53 & 0.0205 \\
\hline 4 & 205828_at & MMP3 & 35.40 & 0.000288 & 26.15 & 0.0141 \\
\hline 5 & 205680_at & MMP10 & 29.51 & 0.00102 & 23.70 & 0.0151 \\
\hline 6 & 222108_at & AMIGO2 & 5.25 & 0.00224 & 3.27 & 0.024 \\
\hline 7 & 201976_s_at & MYO10 & 3.96 & 0.00396 & 2.21 & 0.0333 \\
\hline 8 & 203936_s_at & MMP9 & 13.60 & 0.00438 & 8.39 & 0.0206 \\
\hline 9 & 225681_at & CTHRC1 & 16.01 & 0.00454 & 9.96 & 0.0378 \\
\hline 10 & 225646_at & CTSC & 7.17 & 0.0058 & 4.66 & 0.0319 \\
\hline \multicolumn{7}{|c|}{ Recurrent T vs N } \\
\hline S1 & Affymetrix & Gene & $\mathrm{p}$ & Fold & $\mathrm{p}$ & Fold \\
\hline No & ID & Symbol & (R/Normal) & (R/Normal) & (NR/Normal) & (NR/Normal) \\
\hline 1 & 204567_s_at & ABCG1 & $3.83 \mathrm{E}-05$ & 6.71 & 0.00166 & 3.78 \\
\hline 2 & 205479_s_at & PLAU & 0.00409 & 7.66 & 0.00268 & 4.95 \\
\hline 3 & 203562_at & FEZ1 & 0.00837 & 6.14 & 0.0360 & 3.20 \\
\hline 4 & 225285_at & BCAT1 & 0.0196 & 6.16 & 0.0265 & 3.98 \\
\hline 5 & 212488_at & COL5A1 & 0.0197 & 7.18 & 0.0117 & 5.88 \\
\hline 6 & 205959_at & MMP13 & 0.0205 & 25.45 & 0.0313 & 10.91 \\
\hline 7 & 202998_s_at & LOXL2 & 0.0206 & 5.31 & 0.0452 & 3.69 \\
\hline 8 & 214297_at & CSPG4 & 0.0249 & 5.44 & 0.0144 & 4.18 \\
\hline 9 & 214329_x_at & TNFSF10 & 0.0303 & 4.09 & 0.0312 & 2.96 \\
\hline 10 & 202688_at & TNFSF10 & 0.0360 & 3.96 & 0.0141 & 2.31 \\
\hline
\end{tabular}

30 months; range: 11-49), 20 were classified into Group I, 11 into Group II [median DFS: 16.5 months; range 8-28 months) and 4 into Group III (median DFS: 13 months; range: 2-14 months) (Table 2). Normal oral mucosa from 5 non-diseased subjects was used as control in both the experiments.

Validation was also carried out in 37 saliva samples, 12 controls (median age: 52 years, range 32-81) and 25 patients diagnosed with early stage (T1/T2) oral tongue cancer (median age: 50 years, range: $31-82$ years). The median follow up of the patients was 18 months (range: 10-36 months) (Table 2). Among the T1/T2 patients, 3 showed nodal recurrences and one developed distant metastasis.

\subsection{Gene expression profiles that distinguish recurrent and non recurrent tongue cancer}

Supervised analysis was carried out on the expression profiles obtained from the Affymetrix HGU133 plus 2 arrays. Samples were grouped into Normal/ Tumor, recurrent and non-recurrent for analytical purpose. Hundred and ten genes were differentially regulated in all the tumor samples $(p<0.05), 212$ in nonrecurrent tumors $(p<0.005)$ and 112 in recurrent tumors $(p \leqslant 0.01)$ (Supplementary data, Tables S1, S2, S3).
The statistically significant subset of differentially expressed genes in recurrent tongue cancer include ABCG1, PLAU, COL5A1, FEZ1, while MMP1, 3, 10, SNAI2, PRSS23 were up regulated in non-recurrent group (Table 3). A noticeable feature was the repression of the hemoglobin genes (HBB, HBA1, HBA2) in the recurrent samples and the induction of immune response genes $(\operatorname{Ig} L A, \operatorname{Ig} K C)$ in the non-recurrent set. (Supplementary data, Tables S2 \& S3). The significant functions identified in non-recurrent subset (Ingenuity Pathway Analysis, Ingenuity Systems Inc. CA, USA) were cancer and cell death along with protein degradation/synthesis. Recurrent sample set showed connective tissue disorders, molecular transport and tissue morphology as significant from among the major functions identified (Supplementary Table S4).

The statistically significant lists of genes obtained $(p<0.05)$ were clustered using hierarchical clustering (HC) methods. The recurrent normal and tumor samples were classified by 261 probe sets (Fig. 1A); while a subset of 92 probes classified the tumor samples into resistant/responsive groups (Fig. 1B). $K$-means clustering (KMC) revealed significant clusters which included the immune response genes induced (IGHAI, IGLA, $I G K C)$ in non-recurrent tumors and $H B B / H B A I$ cluster repressed in the recurrent tumor samples (Fig. 1C \& D). Hierarchical clustering of the adjacent mucosal sam- 
A

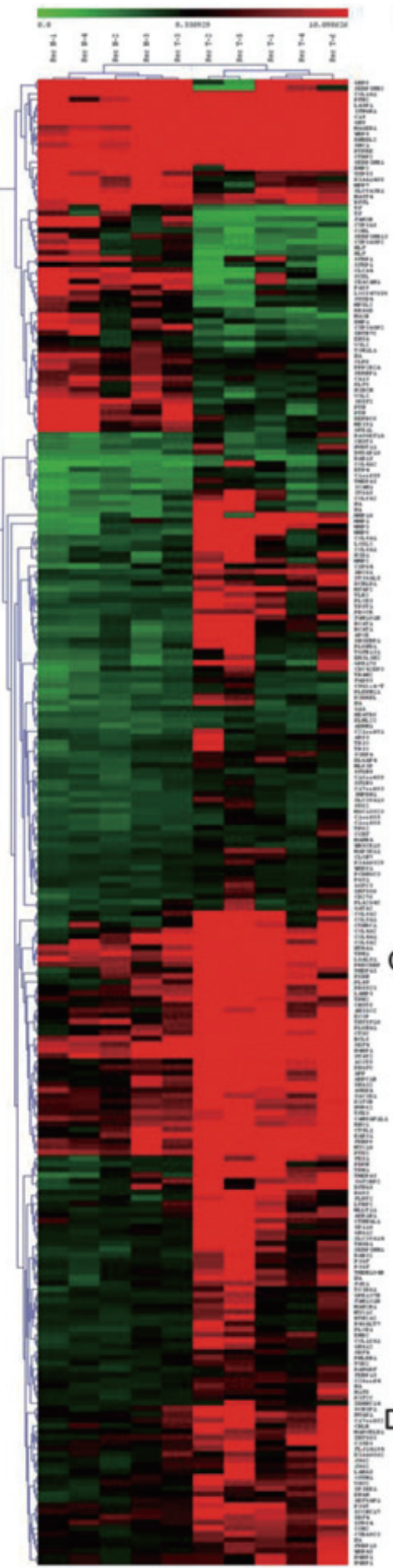

B

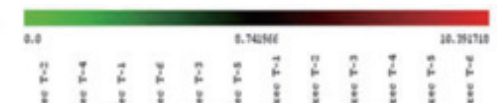

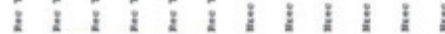
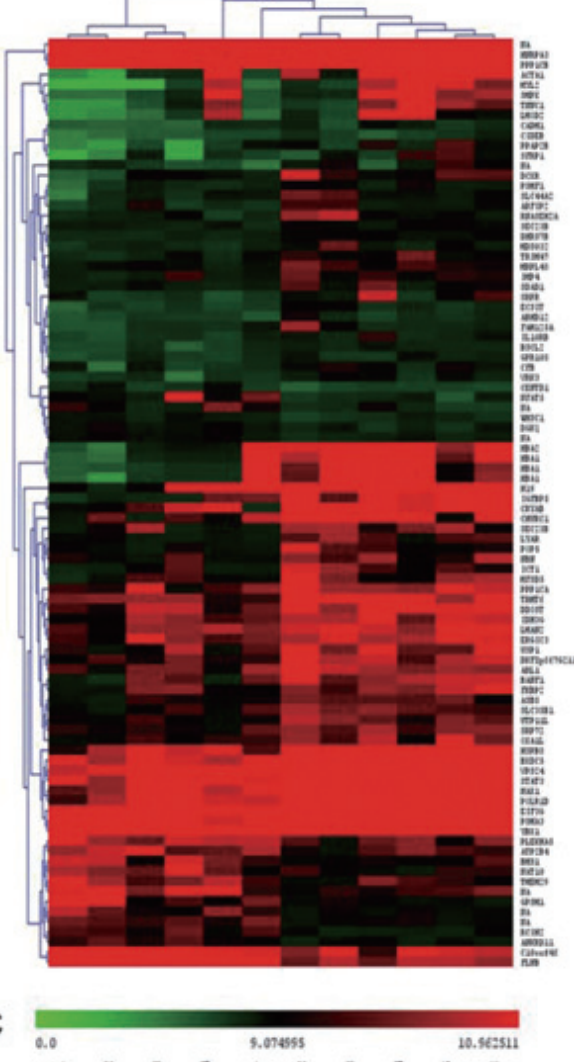

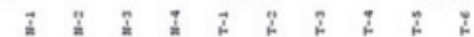
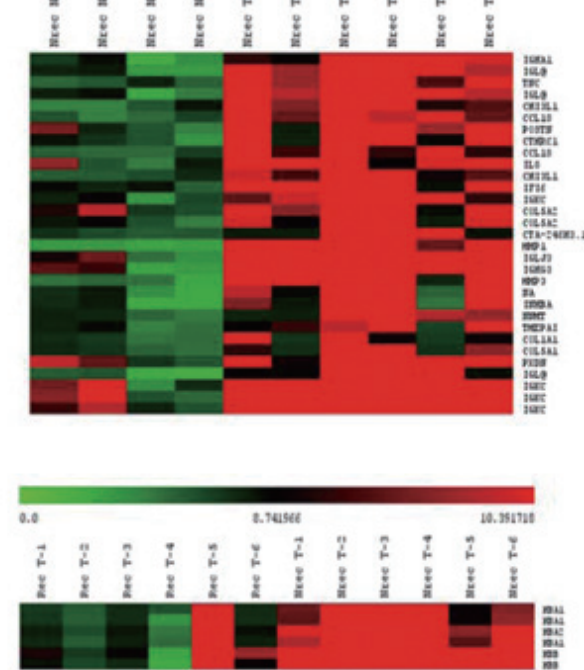

Fig. 1. Hierarchical and $K$-means clustering of differentially expressed genes in recurrent tongue cancer. Clustering analysis was done using $\mathrm{Me} V$ (TIGR) after application of Wilcoxon Mann Whitney test using the Euclidean distance measurement. The clustering analysis revealed classifiers for recurrent tumors (A) and all tumors (B). $K$-means clustering $(\mathrm{K}=10$; Euclidean distance) was also carried out with the distinct clusters of immune response genes up regulated in non recurrent tumors (C) and HBA/HBB clusters down regulated in recurrent tumors (D). 
Table 4

Receiver operating curve and regression analysis of the markers

\begin{tabular}{|c|c|c|c|c|c|}
\hline \multicolumn{6}{|l|}{ ROC analysis } \\
\hline \multirow[t]{2}{*}{$\begin{array}{l}\text { Test result } \\
\text { variable }\end{array}$} & \multirow[t]{2}{*}{ Area } & \multirow[t]{2}{*}{ Std error } & \multicolumn{2}{|c|}{$\begin{array}{l}\text { Asymptotic } 95 \% \\
\text { confidence Interval }\end{array}$} & \multirow[t]{2}{*}{$p$ value } \\
\hline & & & Lower bound & Upper bound & \\
\hline COL5A1 & 0.806 & 0.0793 & 0.650 & 0.961 & 0.0001 \\
\hline IGLA & 0.824 & 0.0822 & 0.622 & 0.985 & 0.0001 \\
\hline HBB & 0.975 & 0.0201 & 0.936 & 1.000 & $<0.0001$ \\
\hline CTSC & 0.746 & 0.0914 & 0.566 & 0.925 & 0.0072 \\
\hline ABCG1 & 0.661 & 0.101 & 0.462 & 0.859 & 0.112 \\
\hline MMP1 & 0.533 & 0.109 & 0.319 & 0.748 & 0.759 \\
\hline EMP1 & 0.464 & 0.11 & 0.249 & 0.679 & 0.745 \\
\hline CCL18 & 0.605 & 0.109 & 0.392 & 0.818 & 0.334 \\
\hline \multicolumn{6}{|c|}{ Regression Analysis } \\
\hline $\begin{array}{l}\text { Independent } \\
\text { variables }\end{array}$ & Coefficient & Std. Error & $t$ & $p$ & \\
\hline (Constant) & -0.02586 & & & & \\
\hline COL5A1 & 0.33410 & 0.108 & 3.092 & 0.0046 & \\
\hline $\mathrm{HBB}$ & 0.67240 & 0.1088 & 6.182 & $<0.0001$ & \\
\hline
\end{tabular}

ples identified 244 probes with specific clusters of transcription factors, regulatory proteins kinases (ZMYM2, SFRS12, HIPK1, RNF12), stem cell associated factors (ANKRD50, ATR) and hemoglobin genes that classified them into recurrent and non-recurrent groups (Fig. 2A, B \& C). Statistical analysis also identified a set of 11 probes that overlapped between the adjacent mucosa and tumor tissue of the recurrent sample set (Fig. 2D).

The ingenuity pathway analysis was carried out in all groups; with $p<0.05$ and Fishers exact test applied as a test of significance. The top 10 canonical pathways identified in the recurrent and the non-recurrent groups after core comparison analysis are represented in Figs 3A and 3B. The most significant pathways include Glioma invasiveness signaling, bladder cancer signaling, LXR/RXR activation and colorectal cancer metastasis signaling in the recurrent group. The nonrecurrent set primarily showed Interferon signaling; Cytotoxic T-lymphocyte mediated apoptosis of target cells, protein ubiquitination and Myc mediated apoptosis as significant pathways. The recurrent profile was characteristic in the absence of these immune response pathways. Network analysis of the differentially expressed genes between the recurrent and non recurrent tumor samples identified two primary interaction networks which showed differential regulation of the target genes of XBP1 and E2F, genes of the troponin family and the interacting partners HBB and HBA1 (Figs 4A and $4 \mathrm{~B})$.

\subsection{Validation of markers}

Validation was carried out for 8 genes, selected based on their $p$-values and clustering ability in all the three study groups. Quantification of the markers was carried out by normalizing their expression to that of the endogenous control (GAPDH) and relative to the expression in the normal mucosa samples (non-diseased controls) using the $\Delta \Delta \mathrm{C}_{T}$ method. The expression profile of four markers COL5A1, IGLA, HBB and CTSC could differentiate between the three study groups, the pattern being similar between the Group II \& III samples (Fig. 5A). Analysis using the Receiver Operating Curve Characteristics (ROC), revealed best empirical area under curve (AUC) for these four markers (Fig. 5B, Table 4) with HBB providing the best predictive power (AUC 0.975; 95\% CI 0.936-1.000, $p=<0.0001$ ). COL5Al $(p=0.004)$ and HBB $(p=0.0001)$ had best predictive power in combination as revealed by multiple regression analysis (Table 4).

Among the 37 saliva samples analyzed, 28 (Normals: 8; T1/T2: 20) were positive for the endogenous controls by Reverse Transcription PCR (RT PCR) and were hence selected for further analysis by quantitative PCR. The expression of the markers was calculated with the normal samples as the calibrator. Sixty-five percent of (13/20) T1/T2 showed expression of one or more of these markers (Fig. 5C). ABCG1, MMP1, COL5A1, $I L 1 B, I L 8$ and FN1 were detected in the tumors. ILIB expression was observed in the normal samples, IGLA was detected in only one tumor sample while FAPA, $H B B$ and SERPINH2 were undetected. ROC analysis of the markers in combination (ABCG1, MMP1, FN1, $C O L 5 A 1, I L 8)$, wherein detection of one or more of the marker was considered a positive outcome) could detect the patients with T1/T2 carcinoma with a sensitivity of 0.65 and specificity of 0.87 (AUC: 0.762) (Fig. 5D). 
A
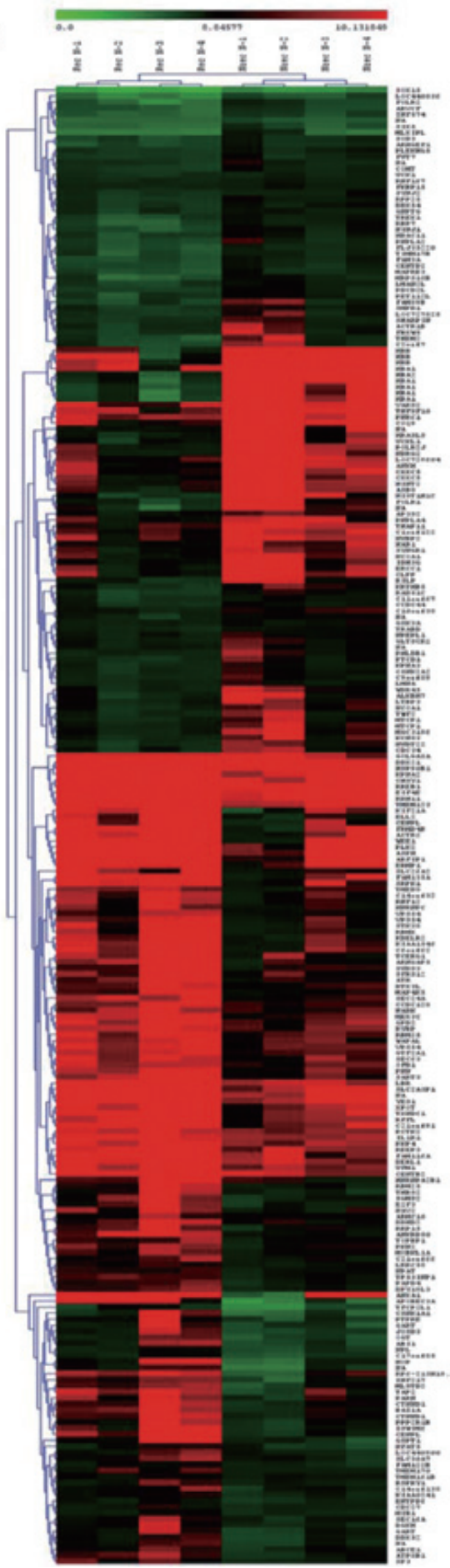

B
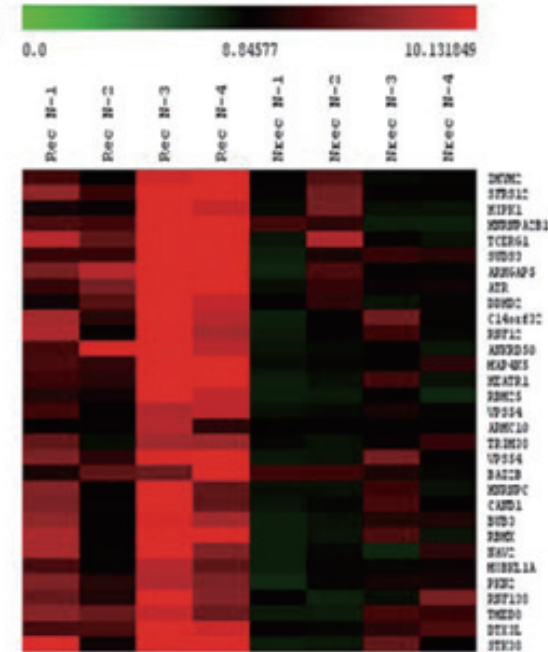

C

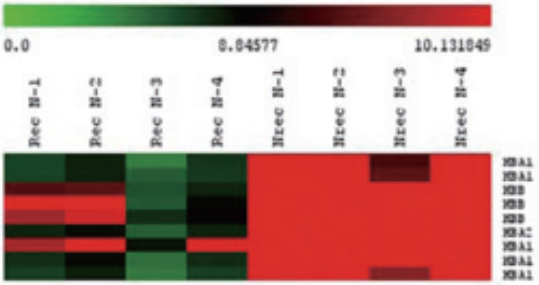

\begin{tabular}{|c|c|c|c|c|c|c|}
\hline . & Afifmetin D & & $\begin{array}{l}\text { Nomal } \\
\text { Mars } \\
\text { forl }\end{array}$ & probe & $\begin{array}{l}\text { Tums } \\
\text { (MRA) Fold }\end{array}$ & prable \\
\hline & $202116, x=2$ & & & 0000 & & \\
\hline 2 & $217280 \times x$ & 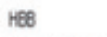 & 2381 & 000056 & 807 & 00083 \\
\hline 3 & $20058 \times x$ & HeA Ir HeN & 2319 & 00083 & 523 & 000378 \\
\hline 4 & $21715, x$ & HEA & $22 \pi 2$ & 00124 & 652 & $003 \%$ \\
\hline 5 & $21100_{-X}$ & HEA IIHEN & 1870 & 00004 & 450 & 00022 \\
\hline 6 & $20018 \times x_{2}$ & HEA IIIBEN & 16.41 & 00038 & 461 & 0044 \\
\hline 7 & $210041, x$ & $\angle O P O$ & 372 & 0048 & 106 & 000659 \\
\hline 8 & 280202 & PPPCB & 304 & 000302 & 200 & 00053 \\
\hline 9 & $200050,8 ., \mathrm{k}$ & PLENHES & .229 & 00055 & 165 & 00053 \\
\hline 10 & $20000,3,2 t$ & NFAT5 & .235 & 000000 & 24 & 0014 \\
\hline & $200000_{\alpha} z$ & - & .279 & 00108 & .153 & 00034 \\
\hline
\end{tabular}

Fig. 2. Differential expression in the adjacent mucosal tissue. Hierarchical clustering between adjacent mucosal tissue revealed extensive differences in expression profiling (A). $K$-means clustering showed the up regulation of a sub-set of genes including stem cell genes such as ATR, ARHGAP5 (B) and down regulation $H B B / H B A 1$ cluster in the recurrent patients (C). Statistical analysis (ANOVA) also revealed a sub set of genes overlapping between the adjacent mucosal tissue and tumor samples of the recurrent patients (D). 

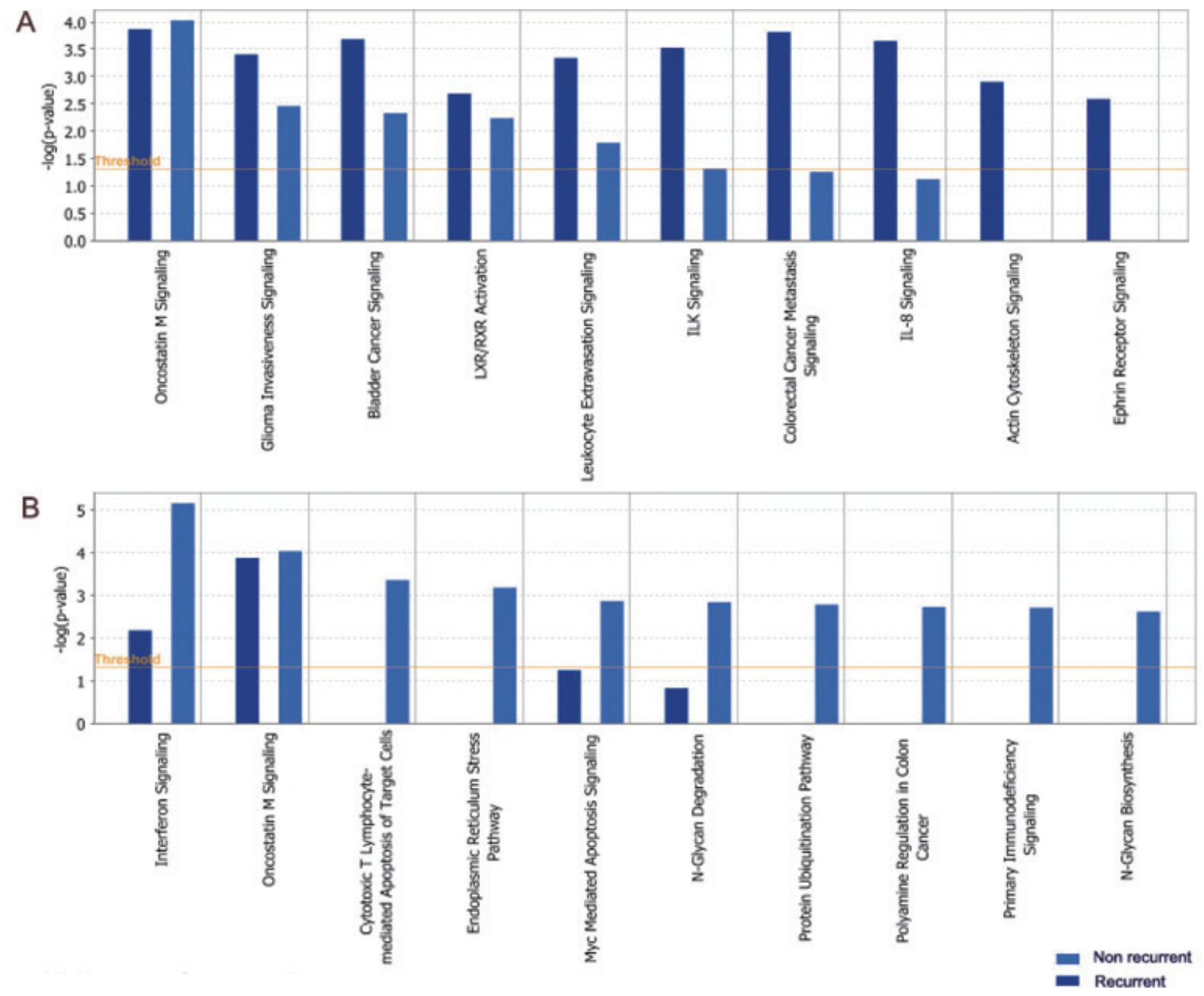

Fig. 3. Significant pathways between Non-recurrent and recurrent tongue cancer. Pathway analysis was carried out by Ingenuity Pathway Analysis (IPA) and the top 10 significant pathways are represented in the figure. The pathways are sorted according to significance in recurrent sub set $(\mathrm{A})$ and non-recurrent samples $(\mathrm{B})$.

Immunohistochemical analysis of two of the markers, COL5A1 and HBB, showed a grade III-IV COL5A1 (intense staining) and grade I-II HBB (mild staining) in the patients of Group III (Fig. 6A) respectively. ROC curve analysis showed that HBB protein expression pattern could predict the resistance/responsive behavior of the Group I and II patients with a sensitivity of 0.84 and a specificity of 0.81 (AUC of 0.870) (Figs 6B \& C).

\section{Discussion}

Tongue cancer is one of the most invasive and aggressive of cancers that occur in the oral cavity, with a high risk of loco-regional failure as compared to other sub-sites. Predicting resistance/response to treatment is vital in order to devise personalized protocols for patients and in this context, the ability of molecular markers to improve the prognostication provided by the current staging system gains significance. A set of highly specific and sensitive molecular markers that detect the small percentage of cells that are treatment resistant will be a step towards accurate prognosis. These resistant cells are enriched in the post treatment recurrent tissue due to the significant reduction in the sensitive cells as per the 'log kill effect'. Our study attempts to identify markers that specify these resistant cells and focuses on evaluating their efficacy in treatment outcome prediction and their utility as salivary markers.

Expression profiling using the Affymetrix system and other platforms have documented the transcriptome 

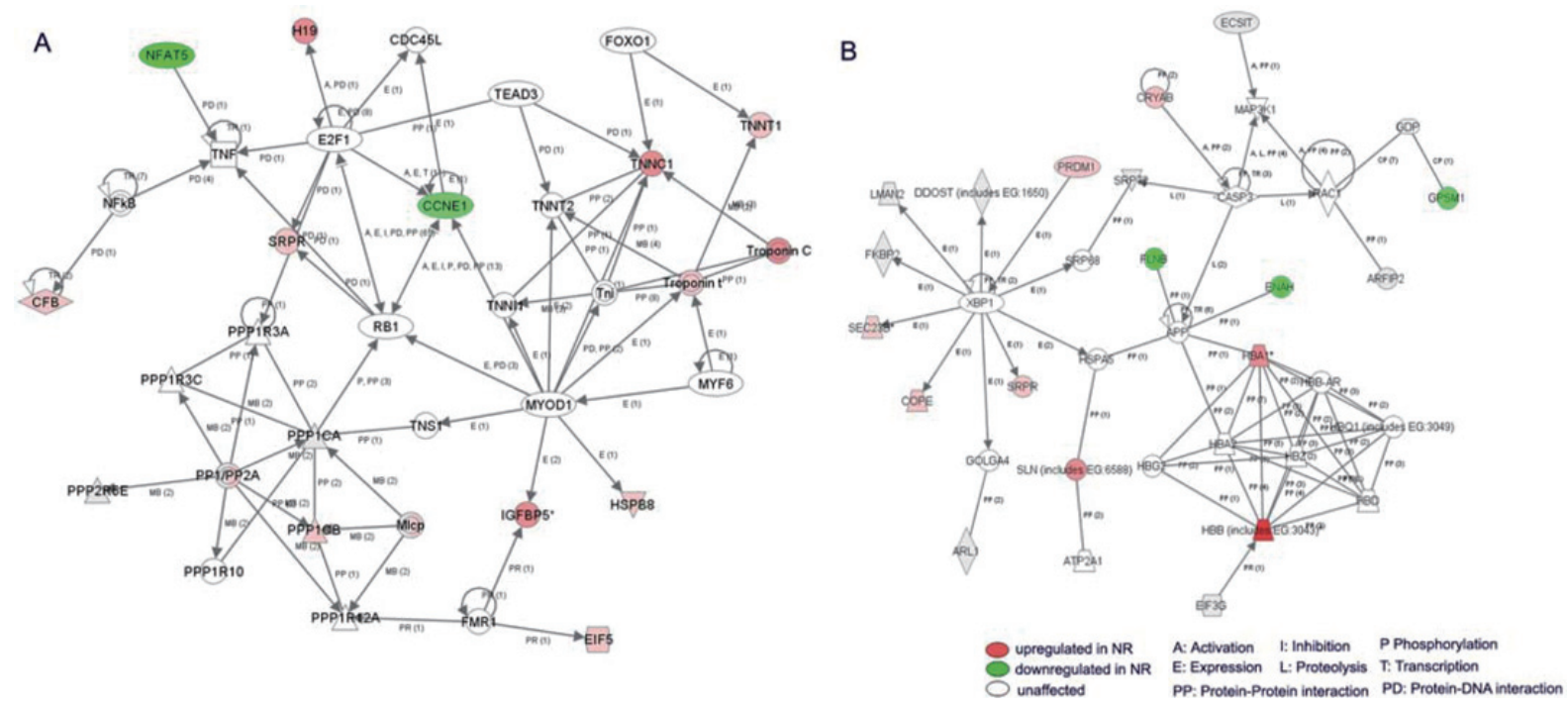

Fig. 4. Interaction networks identified by Ingenuity Pathway Analysis. Interaction network of genes that are differentially expressed between Non-recurrent and recurrent tumors (A \& B). The symbols in the figure denote the following A: Activation, E: Expression, PP: protein-Protein Interaction, I: Inhibition, L: Proteolysis; P: Phosphorylation, T: Transcription, PD: Protein-DNA interaction. Note the group of genes, the expression of which is dependent upon XBP1 and E2F (A). The binding partners HBB and HBA1 are both higher in expression in non-recurrent tumors (B).
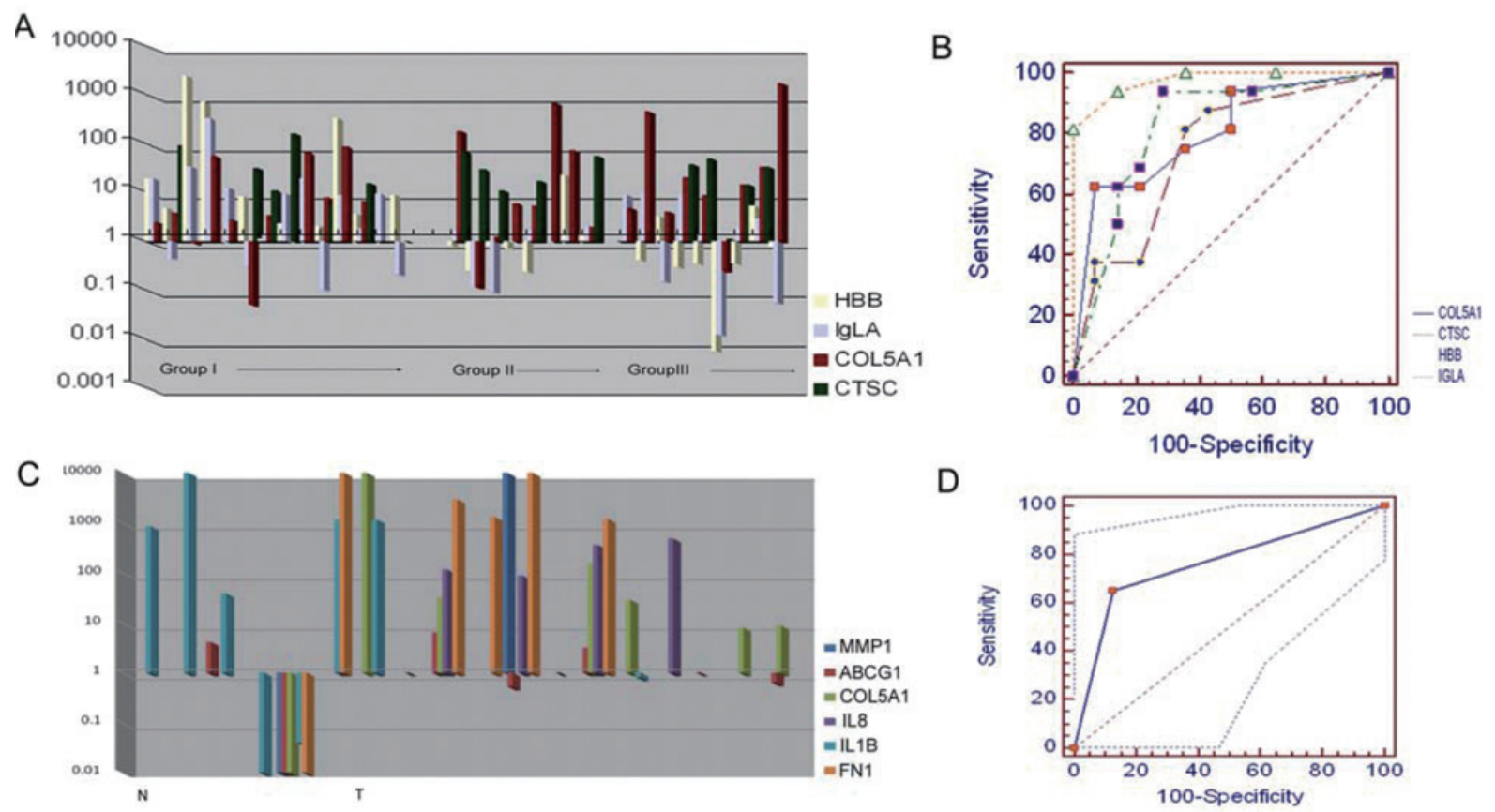

Fig. 5. Validation in tissues and saliva samples. The expression profile of a select subset of markers was validated in tongue cancer specimens (A). A distinct difference in expression profile of 4 genes (COL5A1, IGLA, HBB, and CTSC) was observed in the primary tissue of patients that were non-recurrent (Group I) and recurrent (Group II). The pattern of expression obtained in the patients of the latter group was similar to that obtained in the recurrent tissue of patients (Group III). ROC analysis revealed these markers as most significant according to the AUC (B). The profile of 6 genes in saliva samples from normal $(\mathrm{N})$ and tumor $(\mathrm{T})$ samples is shown $(\mathrm{C})$. The normal samples primarily show the expression of $I L 1 B$ while at least one of the carcinogenesis related genes are expressed in the patients. ROC analysis of the combination of markers ( $A B C G 1$, IL8, COL5AI, FN1, and MMPI) shows sensitivity of 0.65 and specificity of 0.87 (D). 

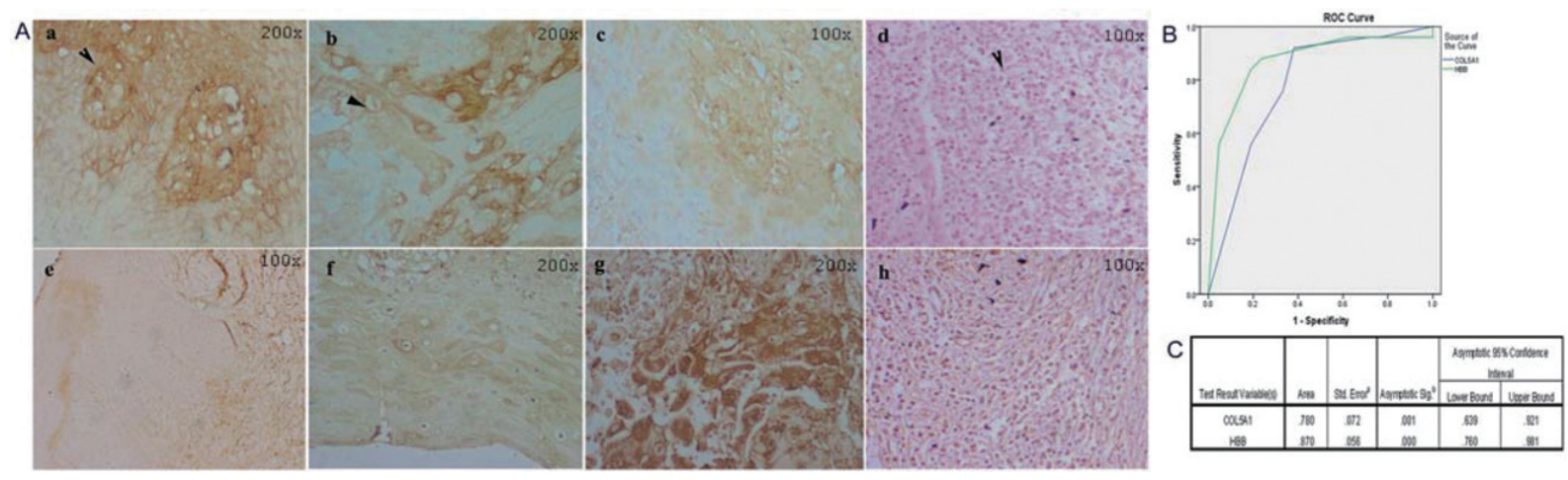

Fig. 6. Immunohistochemical analysis of candidate markers. IHC was carried out on tongue cancer samples (A) with antibodies to $H B B$ (a, b, c, d) and COL5A1 (e, f, g, h). The expression was analyzed in normal controls (a, e), in non-recurrent tumor samples (b \& f) and in recurrent samples $(\mathrm{c} \& \mathrm{~g}) . \mathrm{d} \& \mathrm{~h}$ represent negative controls. The non-recurrent tumor sample showed a high expression of $H B B$ as observed in the normal control; while an over expression of COL5A1 was observed in the recurrent tumor sample. The magnifications (100 or 200 times the original magnification) are mentioned on each panel. ROC analysis showed $H B B$ as a better candidate marker as compared to COL5A1 (B \& C).

pattern of head and neck squamous cell carcinoma in general $[16,17]$, tongue cancer in particular $[18,19]$ and its metastatic/recurrent forms [20]. MMPs, specifically $M M P 1$, which showed the highest fold level elevation in both recurrent and non-recurrent tongue tumors in this study, has been reported as significant in oral tumorigenesis previously [21,22]. Ginos et al. have previously reported an absence of immune signature in recurrent head and neck cancer patients [23]; a similar pattern is observed in this study as revealed by the IPA analysis. A significant up regulation of pathways associated with immune response such as Interferon signaling, Cytotoxic T lymphocyte mediated apoptosis and Oncostatin $\mathrm{M}$ signaling was observed in the non-recurrent tumors. Previous studies have reported these pathways to be associated with relapse free survival in breast cancers and in adoptive immune therapy [24,25]. Network analysis of the differentially expressed genes between non recurrent and recurrent tumors, identified the troponin family (TNNT, TNNC), as up regulated in the former, of which Troponin 1 is a known angiogenic inhibitor [26]. $C C N E 1$, identified previously as a marker of poor response to treatment [27], was down regulated in these tumors. The analyses also revealed a dysregulation of the hemoglobin genes ( $H B B, H B A 1$, and $H B A 2)$ and the targets of XBP1 such as PRDM1, SEC23B, previously identified as differentially expressed in chemoresistant leukemias, lymphomas and pancreatic cancers [28-30]. $N F A T 5$ and $E N A H$, reported as involved in invasion and metastasis during carcinogenesis were down regulated in the non recurrent tumors [31-33].

The adjacent mucosa of the non-recurrent and recurrent groups showed a differential expression; probably indicating the effect of field cancerization. The mucosa from the recurrent subgroup showed a distinct induction of a group of transcription factors, Zinc finger proteins and regulatory proteins. Among the markers identified, ZMYM2 (Zinc finger MYM type-2) has been reported as an early indicator of carcinogenesis in adjacent mucosa of colorectal cancer and SFRS12 (splicing regulatory glutamine/lysine-rich protein) in its progression [34, 35]. A subset of genes with known expression in epithelial and embryonic stem cells was also induced in adjacent mucosa of recurrent tumors (ATR, ARHGAP5, and ANKRD50). Ataxia telangiectasia mutated and Rad3-related (ATR) promotes cell cycle progression in the presence of double stranded DNA breaks [36]. A loss in its activity enhances chemo sensitivity and reduces cancer cell survival [37], while a knockdown in mice reduces the number and renewal/homeostatic capacity of the tissue-specific stem cells [38]. Ankyrin repeat domain 50 (ANKRD50) and Rho GTPase Activating protein 5 (ARHGAP5) are upregulated in epidermal stem cells and neural progenitor cells respectively $[39,40]$. The over expression of these markers in the adjacent mucosal tissue of the resistant tumor set in this study, supports the field cancerization concept and attributes the ineffectiveness of therapy and the subsequent loco-regional recurrence of the disease to the residual and resistant stem cell-like population. This also demonstrates that histologically negative adjacent mucosal tissue may have undergone molecular changes. Consequently, the validation of the markers identified by the micro array platform in this study was carried out using normal oral mucosa as controls.

Among the genes selected for validation, COL5A1, $H B B, C T S C$ and IGLA showed an expression profile specific to the resistant tumors. COL5A1, a determi- 
nant of the stromal component of the tumor is known to contribute to the carcinogenic and metastatic processes as inferred by previous studies [41]. $H B B$ has been attributed with tumor suppressor activities and is also designated as a survival factor in a number of cancers. Loss of Heterozygosity ( $\mathrm{LOH}$ ) of the $H B B$ locus (11p15.5) has been reported in lung, breast and ovarian cancers [42-44]. Reduced $H B B$ expression is observed in lung adenocarcinomas [45] and is associated with poor prognosis in non-small cell lung cancer [46]. Anaplastic thyroid cancer cell lines/tissues show a repression of $H B B$, while its exogenous expression in cell lines is known to lead to suppression of growth [47]. IgLA, the immune response gene, was over expressed in the tumors that responded to treatment in this study. Although this expression profile might be indicative of other conditions (tissue differences, disease status), the presence of a healthy immune response may indeed be indicative of a better prognosis as reported in cancers of the breast and head and neck $[23,48]$. Cathepsin C $(C T S C)$, a cysteine protease that functions in terminal protein degradation and facilitates invasive growth, is also validated in this study and has been previously reported as up regulated in solid tumors [49]. The pattern of expression of these validated genes was similar between primary tumor samples collected from patients who developed recurrence during the follow-up period (Group II), and recurrent tumor specimens (Group III), indicating that an accurate prognosis of treatment response can be arrived at based on the primary tumor signature.

$M M P 1, E M P 1, C C L 18$ and $A B C G 1$ were among the genes that could not discriminate between the different study groups in the validation cohort. MMPI has been identified as a possible marker of progression in ovarian carcinomas and SNPs in the gene were associated with treatment response in ovarian and lung cancer [50, 51], while EMP1,CCL18 and ABCG1 are reported to be differentially regulated in solid tumors such as head and neck and cervix [16,52-54] previously. However, in this study, though the expression profile was distinct in the tumor samples (both recurrent and non recurrent) as compared to the adjacent mucosa, the patterns obtained were not conclusive in discriminating the recurrent subset of patients. $A B C G 1$ was over expressed in the recurrent tumor set but the profile in the untreated primary was not predictive of treatment response.

Expression profiling of tissue biomarkers in saliva enables us to evaluate their efficacy in salivary diagnostics. RNA integrity was ensured by expression of the endogenous control; $75 \%$ of the samples thus qual- ified for analysis. A subset of the markers identified as differentially expressed in oral cancer and its recurrent form were detected in the cell-free saliva of tongue cancer patients. Among these genes, IL 8 and $I L I B$ have been previously identified as significant in oral cancer patients [8] The relatively higher expression of $I L I B$ in the non-cancerous controls can be attributed to the fact that its expression can also be induced by inflammatory conditions [55]. This further emphasizes that the use of a panel of markers improves the efficacy of the diagnosis. The expression of only a subset of the tumor markers in saliva indicates that the genes differentially expressed in tumors need to be screened thoroughly to enable their application in salivary diagnostics. A prospective study in a larger cohort of patients is currently ongoing in the laboratory to establish the clinical relevance of the expression of the markers specific to resistance/response (COL5Al) in saliva.

Identification of a set of markers that would predict oral tongue tumors resistant to treatment modalities and hence susceptible for recurrent behavior will have significant clinical benefit. Our study provides evidence that a specific panel of markers is indeed effective in predicting recurrence, their detection in saliva suggesting that further exploration of salivary markers in prognostics may provide concrete results. Further expression studies in tissues from patients and their corresponding saliva samples are warranted to identify new candidate biomarkers which would increase the sensitivity and specificity of treatment outcome prediction.

\section{Acknowledgement}

Financial Assistance from Council of Scientific and Industrial Research (CSIR), India is acknowledged.

\section{Conflict of Interest Statement}

None declared

\section{Supplemental material}

Supplementary data can be found at: http://mazum darshawcancercenter.files.wordpress.com/2011/09/ supplementary-data.xls.

\section{References}

[1] S.R. Moore, N.W. Johnson, A.M. Pierce and D.F. Wilson, The epidemiology of tongue cancer: a review of global incidence, 
Oral Diseases 6 (2000), 75-84

[2] W. Jerjes, T. Upile, A. Petrie, A. Riskalla, Z. Hamdoon, M. Vourvachis, K. Karavidas, A. Jay, A. Sandison, G.J. Thomas, N. Kalavrezos and C. Hopper, Clinicopathological parameters, recurrence, locoregional and distant metastasis in 115 T1-T2 oral squamous cell carcinoma patients, Head Neck Oncol 2 (2010), 9.

[3] G.L. Day and W.J. Blot, Second primary tumors in patients with oral cancer, Cancer 70 (1992), 14-19.

[4] R. Ralhan, Diagnostic Potential of Genomic and Proteomic Signatures in Oral Cancer, Int J Hum Genet 7 (2007), 57-66.

[5] P. Choi and C.P. Chen, Genetic Expression Profiles and Biologic Pathway Alterations in Head and Neck Squamous Cell Carcinoma, Cancer 104 (2005), 1113.

[6] E.M. Starke, J.C. Smoot, J.H. Wu, W.T. Liu, D. Chandler and D.A. Stahl, Saliva-based diagnostics using 16S rRNA microarrays and microfluidics, Ann N Y Acad Sci 1098 (2007), 345-361.

[7] B.G. Zimmermann, N.J. Park and D.T. Wong, Genomic targets in saliva, Ann N Y Acad Sci 1098 (2007), 184-191.

[8] Y. Li, M.A. St. John, X. Zhou, Y. Kim, U. Sinha, R.C.K. Jordan, D. Eisele, E. Abemayor, D. Elashoff, N. Park and D.T. Wong, Salivary Transcriptome Diagnostics for Oral Cancer Detection, Clinical Cancer Research 10 (2004), 8442-8450.

[9] Y. Li, X. Zhou, M.A.R. St. John and D.T.W. Wong, RNA Profiling of Cell-free Saliva Using Microarray Technology, $J$ Dent Res 83 (2004), 199-203.

[10] G. Sun and F.Y. Ping, Application of saliva protein fingerprints in the diagnosis of oral squamous cell cancer by surface enhanced laser desorption ionization time of flight mass, Zhonghua Kou Qiang Yi Xue Za Zhi 44 (2009), 664-667.

[11] H. Xie, G. Onsongo, J. Popko, E.P. de Jong, J. Cao, J.V. Carlis, R.J. Griffin, N.L. Rhodus and T.J. Griffin, Proteomics analysis of cells in whole saliva from oral cancer patients via value-added three-dimensional peptide fractionation and tandem mass spectrometry, Mol Cell Proteomics 7 (2008), 486-498.

[12] E.P. de Jong, H. Xie, G. Onsongo, M.D. Stone, X.B. Chen, J.A. Kooren, E.W. Refsland, R.J. Griffin, F.G. Ondrey, B. Wu, C.T. Le, N.L. Rhodus, J.V. Carlis and T.J. Griffin, Quantitative proteomics reveals myosin and actin as promising saliva biomarkers for distinguishing pre-malignant and malignant oral lesions, PLoS One 5, e11148.

[13] R.A. Irizarry, B.M. Bolstad, F. Collin, L.M. Cope, B. Hobbs and T.P. Speed, Summaries of Affymetrix GeneChip probe level data, Nucleic Acids Res 31 (2003), e15.

[14] A.I. Saeed, V. Sharov, J. White, J. Li, W. Liang, N. Bhagabati, J. Braisted, M. Klapa, T. Currier, M. Thiagarajan, A. Sturn, M. Snuffin, A. Rezantsev, D. Popov, A. Ryltsov, E. Kostukovich, I. Borisovsky, Z. Liu, A. Vinsavich, V. Trush and J. Quackenbush, TM4: a free, open-source system for microarray data management and analysis, Biotechniques 34 (2003), 374-378.

[15] K.J. Livak and T.D. Schmittgen, Analysis of relative gene expression data using real-time quantitative PCR and the 2(Delta Delta C (T)) Method, Methods 25 (2001), 402-408.

[16] M.A. Kuriakose, W.T. Chen, Z.M. He, A.G. Sikor, P. Zhang, Z.Y. Zhang, W.L. Qiu, D.F. Hsu, C. McMunn-Coffran, S.M. Brown, E.M. Elango and M.D. Delacure, Selection and validation of differentially expressed genes in head and neck cancer, Cell Mol Life Sci 61 (2004), 1372-1383.

[17] E. Mendez, C. Cheng, D.G. Farwell, S. Ricks, S.N. Agoff, N.D. Futran, E.A. Weymuller, N.C. Maronian, L.P. Zhao and C. Chen, Transcriptional expression profiles of oral squamous cell carcinomas, Cancer 95 (2002), 1482-1494.
[18] C.L. Estilo, P. O-charoenrat, S. Talbot, N.D. Socci, D.L. Carlson, R. Ghossein, T. Williams, Y. Yonekawa, Y. Ramanathan, J.O. Boyle, D.H. Kraus, S. Patel, A.R. Shaha, R.J. Wong, J.M. Huryn, J.P. Shah and B. Singh, Oral tongue cancer gene expression profiling: Identification of novel potential prognosticators by oligonucleotide microarray analysis, BMC Cancer 9 (2009), 11.

[19] F. Carinci, L. Lo Muzio, A. Piattelli, C. Rubini, F. Chiesa, F. Ionna, A. Palmieri, E. Maiorano, A. Pastore, G. Laino, M. Dolci and F. Pezzetti, Potential markers of tongue tumor progression selected by cDNA microarray, Int J Immunopathol Pharmacol 18 (2005), 513-524.

[20] X. Zhou, S. Temam, M. Oh, N. Pungpravat, B.L. Huang, L. Mao and D.T. Wong, Global expression-based classification of lymph node metastasis and extracapsular spread of oral tongue squamous cell carcinoma, Neoplasia 8 (2006), 925-932.

[21] P. O-charoenrat, P.H. Rhys-Evan and S.A. Eccles, Expression of matrix metalloproteinases and their inhibitors correlate with invasion and metastasis in squamous cell carcinoma of the head and neck, Arch Otolaryngol Head Neck Surg 127 (2001), 813-820.

[22] C.Y. Yen, C.H. Chen, C.H. Chang, H.F. Tseng, S.Y. Liu, L.Y. Chuang, C.H. Wen and H.W. Chang, Matrix metalloproteinases (MMP) 1 and MMP10 but not MMP12 are potential oral cancer markers, Biomarkers 14 (2009), 244-249.

[23] M.A. Ginos, G.P. Page, B.S. Michalowicz, K.J. Patel, S.E. Volker, S.E. Pambuccian, F.G. Ondrey, G.L. Adams and P.M. Gaffney, Identification of a Gene Expression Signature Associated with Recurrent Disease in Squamous Cell Carcinoma of the Head and Neck, Cancer Research 64 (2004), 55-63.

[24] M.L. Ascierto, M. Kmieciak, M.O. Idowu, R. Manjili, Y.Zhao, M. Grimes, C. Dumur, E. Wang, V. Ramakrishnan, X.Y. Wang, H.D. Bear, F.M. Marincola and M.H. Manjili, A signature of immune function genes associated with recurrence-free survival in breast cancer patients, Breast Cancer Res Treat 2011 Apr 11. [Epub ahead of print].

[25] J.M. Seeger, P. Schmidt, K. Brinkmann, A.A. Hombach, O. Coutelle, P. Zigrino, D. Wagner-Stippich, C. Mauch, H. Abken, M. Kronke and H. Kashkar, The proteasome inhibitor bortezomib sensitizes melanoma cells toward adoptive CTL attack, Cancer Res 70, 1825-1834.

[26] M.A. Moses, D. Wiederschain, I. Wu, C.A. Fernandez, V. Ghazizadeh, W.S. Lane, E. Flynn, A. Sytkowski, T. Tao and R. Langer, Troponin I is present in human cartilage and inhibits angiogenesis, Proc Natl Acad Sci U S A 96 (1999), 2645-2650.

[27] D. Etemadmoghadam, A. deFazio, R. Beroukhim, C. Mermel, J. George, G. Getz, R. Tothill, A. Okamoto, M.B. Raeder, P. Harnett, S. Lade, L.A. Akslen, A.V. Tinker, B. Locandro, K. Alsop, Y.E. Chiew, N. Traficante, S. Fereday, D. Johnson, S. Fox, W. Sellers, M. Urashima, H.B. Salvesen, M. Meyerson, D. Bowtell and A.S. Group, Integrated genome-wide DNA copy number and expression analysis identifies distinct mechanisms of primary chemoresistance in ovarian carcinomas, Clin Cancer Res 15 (2009), 1417-1427.

[28] Y. Ichikawa, M. Hirokawa, N. Aiba, N. Fujishima, A. Komatsuda, H. Saitoh, M. Kume, I. Miura and K. Sawada, Monitoring the expression profiles of doxorubicin-resistant K562 human leukemia cells by serial analysis of gene expression, Int J Hematol 79 (2004), 276-282.

[29] W.L. Zhao, Y.Y. Liu, Q.L. Zhang, L. Wang, C. Leboeuf, Y.W. Zhang, J. Ma, J.F. Garcia, Y.P. Song, J.M. Li, Z.X. Shen, Z. Chen, A. Janin and S.J. Chen, PRDM1 is involved in chemoresistance of T-cell lymphoma and down-regulated by the proteasome inhibitor, Blood 111 (2008), 3867-3871. 
[30] M. Akada, T. Crnogorac-Jurcevic, S. Lattimore, P. Mahon, R. Lopes, M. Sunamura, S. Matsuno and N.R. Lemoine, Intrinsic Chemoresistance to Gemcitabine Is Associated with Decreased Expression of BNIP3 in Pancreatic Cancer, Clin Cancer Res 11 (2005), 3094-3101.

[31] S. Jauliac, C. Lopez-Rodriguez, L.M. Shaw, L.F. Brown, A. Rao and A. Toker, The role of NFAT transcription factors in integrin-mediated carcinoma invasion, Nat Cell Biol 4 (2002), 540-544.

[32] T.H. Kim, H.I. Kim, Y.H. Soung, L.A. Shaw and J. Chung, Integrin (alpha6beta4) signals through Src to increase expression of S100A4, a metastasis-promoting factor: implications for cancer cell invasion, Mol Cancer Res 7 (2009), 1605-1612.

[33] U. Philippar, E.T. Roussos, M. Oser, H. Yamaguchi, H.D. Kim, S. Giampieri, Y. Wang, S. Goswami, J.B. Wyckoff, D.A. Lauffenburger, E. Sahai, J.S. Condeelis and F.B. Gertler, A Mena invasion isoform potentiates EGF-induced carcinoma cell invasion and metastasis, Dev Cell 15 (2008), 813-828.

[34] Y. Hong, K.S. Ho, K.W. Eu and P.Y. Cheah, A susceptibility gene set for early onset colorectal cancer that integrates diverse signaling pathways: implication for tumorigenesis, Clin Cancer Res 13 (2007), 1107-1114.

[35] A. Provenzani, R. Fronza, F. Loreni and A. Pascale, Global alterations in mRNA polysomal recruitment in a cell model of colorectal cancer progression to metastasis, Carcinogenesis 27 (2006), 1323-1333.

[36] P.J. Hurley, D. Wilsker and F. Bunz, Human cancer cells require ATR for cell cycle progression following exposure to ionizing radiation, Oncogene 26 (2007), 2535-2542.

[37] D. Wilsker and F. Bunz, Loss of ataxia telangiectasia mutated- and Rad3-related function potentiates the effects of chemotherapeutic drugs on cancer cell survival, Mol Cancer Ther 6 (2007), 1406-1413.

[38] Y. Ruzankina, C. Pinzon-Guzman, A. Asare, T. Ong, L. Pontano, G. Cotsarelis, V.P. Zediak, M. Velez, A. Bhandoola and E.J. Brown, Deletion of the developmentally essential gene ATR in adult mice leads to age-related phenotypes and stem cell loss, Cell Stem Cell 1 (2007), 113-126.

[39] K.B. Jensen and F.M. Watt, Single-cell expression profiling of human epidermal stem and transit-amplifying cells: Lrig1 is a regulator of stem cell quiescence, Proc Natl Acad Sci U S A 103 (2006), 11958-11963.

[40] U. Gurok, C. Steinhoff, B. Lipkowitz, H. Ropers, C. Scharff and U.A. Nuber, Gene Expression Changes in the Course of Neural Progenitor Cell Differentiation, The J Neurosc $\mathbf{2 4}$ (2004), 5982-6002.

[41] H. Ye, T. Yu, S. Temam, B.L. Ziober, J. Wang, J.L. Schwartz, L. Mao, D.T. Wong and X. Zhou, Transcriptomic dissection of tongue squamous cell carcinoma, BMC Genomics 6 (2008), 69.

[42] L. Xu, L.C. Wu, F. Du, A. Davis, M. Peyton, Y. Tomizawa, A. Maitra, G. Tomlinson, A.F. Gazdar, B.E. Weissman, A.M. Bowcock, R. Baer and J.D. Minna, Inactivation of human SRBC, located within the 11p15.5-p15.4 tumor suppressor region, in breast and lung cancers, Cancer Research 61 (2001), 7943-7949.

[43] D. Roy, G. Calaf and T.K. Hei, Allelic imbalance at 11p15.515.4 correlated with $\mathrm{c}$-Ha-ras mutation during radiationinduced neoplastic transformation of human breast epithelial cells, Int J Cancer 103 (2003), 730-737.
[44] V. Launonen, A. Mannermaa, F. Stenback, V.M. Kosma, U. Puistola, P. Huusko, M. Anttila, R. Bloigu, S. Saarikoski, A. Kauppila and R. Winqvist, Loss of heterozygosity at chromosomes 3, 6, 8, 11, 16, and 17 in ovarian cancer: correlation to clinicopathological variables, Cancer Genet Cytogenet 122 (2000), 49-54.

[45] J.H. Rho, M.H. Roehrl and J.Y. Wang, Glycoproteomic analysis of human lung adenocarcinomas using glycoarrays and tandem mass spectrometry: differential expression and glycosylation patterns of vimentin and fetuin A isoforms, Protein $J$ 28 (2009), 148-160.

[46] G. Bepler, A. Gautam, L.M. McIntyre, A.F. Beck, D.S. Chervinsky, Y.C. Kim, D.M. Pitterle and A. Hyland, Prognostic significance of molecular genetic aberrations on chromosome segment 11p15.5 in non-small-cell lung cancer, J Clin Oncol 20 (2002), 1353-1360.

[47] M. Onda, J. Akaishi, S. Asaka, J. Okamoto, S. Miyamoto, K. Mizutani, A. Yoshida, K. Ito and M. Emi, Decreased expression of haemoglobin beta (HBB) gene in anaplastic thyroid cancer and recovery of its expression inhibits cell growth, British Journal of Cancer 92 (2005), 2216-2224.

[48] A.E. Teschendorff, A. Miremadi, S.E. Pinder, I.O. Ellis and C. Caldas, An immune response gene expression module identifies a good prognosis subtype in estrogen receptor negative breast cancer, Genome Biology 8 (2007), R157.1-R157.16.

[49] J.A. Joyce, A. Baruch, K. Chehade, N. Meyer-Morse, E. Giraudo, F. Tsai, D.C. Greenbaum, J.H. Hager, Bogyo and D. Hanahan, Cathepsin cysteine proteases are effectors of invasive growth and angiogenesis during multistage tumorigenesis, Cancer Cell 5 (2004), 443-453.

[50] B. Têtu, I. Popa, I. Bairati, S. L'Esperance, M. Bachvarova, M. Plante, F. Harel and D. Bachvarov, Immunohistochemical analysis of possible chemoresistance markers identified by micro-arrays on serous ovarian carcinomas, Mod Pathol 21 (2008), 1002-1010.

[51] D.B. Scherf, H. Dally, P. Müller, G. Werle-Schneider, B. Jäger, L. Edler, S. Tuengerthal, J.R. Fischer, P. Drings, H. Bartsch and A. Risch, Single nucleotide polymorphisms in matrix metalloproteinase genes and lung cancer chemotherapy response and prognosis, Eur Respir J 35 (2010), 381-390.

[52] T. Rajkumar, K. Sabitha, N. Vijayalakshmi, S. Shirley, M.V. Bose, G. Gopal and G. Selvaluxmy, Identification and validation of genes involved in cervical tumourigenesis, BMC Cancer 11 (2011), 80.

[53] J. Zhang, W. Cao, Q. Xu and W.T. Chen, The expression of EMP1 is downregulated in oral squamous cell carcinoma and possibly associated with tumour metastasis, J Clin Pathol 64 (2011), 25-29.

[54] H.E. Gonzalez, M. Gujrati, M. Frederick, Y. Henderson, J. Arumugam, P.W. Spring, K. Mitsudo, H. Kim and G.L. Clayman, Identification of 9 Genes Differentially Expressed in Head and Neck Squamous Cell Carcinoma, Arch Otolaryngol Head Neck Surg 129 (2003), 754-759.

[55] S. Offenbacher, S.P. Barros, D.W. Paquette, J.L. Winston, A.R. Biesbrock, R.G. Thomason, R.D. Gibb, A.W. Fulmer, J.P. Tiesman, K.D. Juhlin, S.L. Wang, T.D. Reichling, K.S. Chen and B. Ho, Gingival transcriptome patterns during induction and resolution of experimental gingivitis in humans, J Periodontol 80 (2009), 1963-1982. 


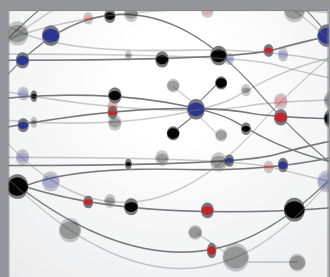

The Scientific World Journal
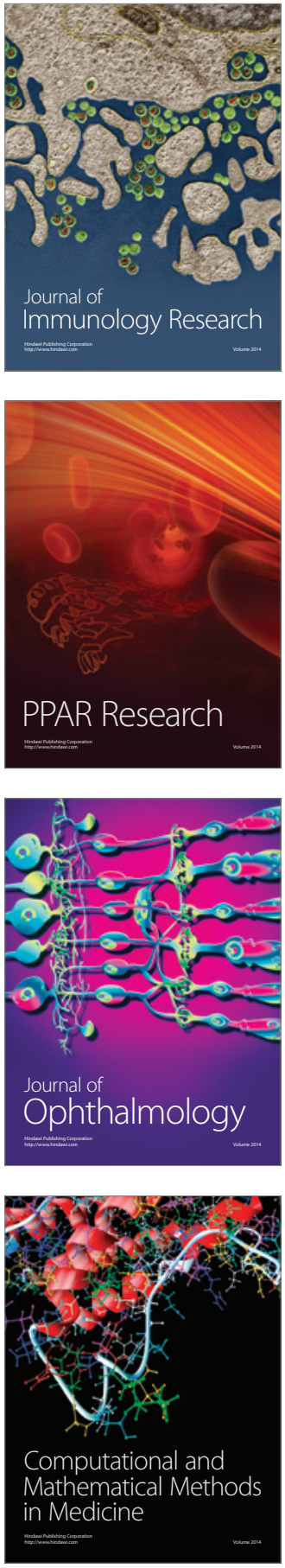

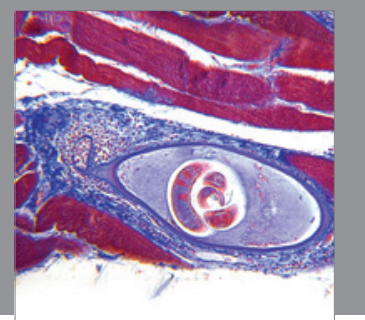

Gastroenterology

Research and Practice
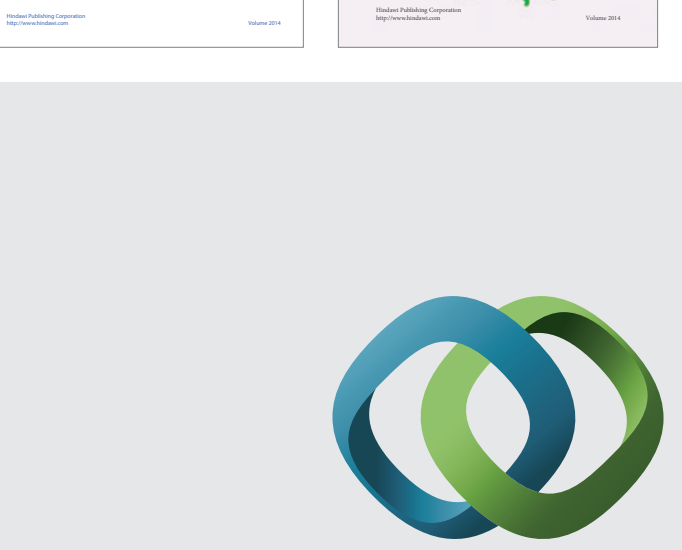

\section{Hindawi}

Submit your manuscripts at

http://www.hindawi.com
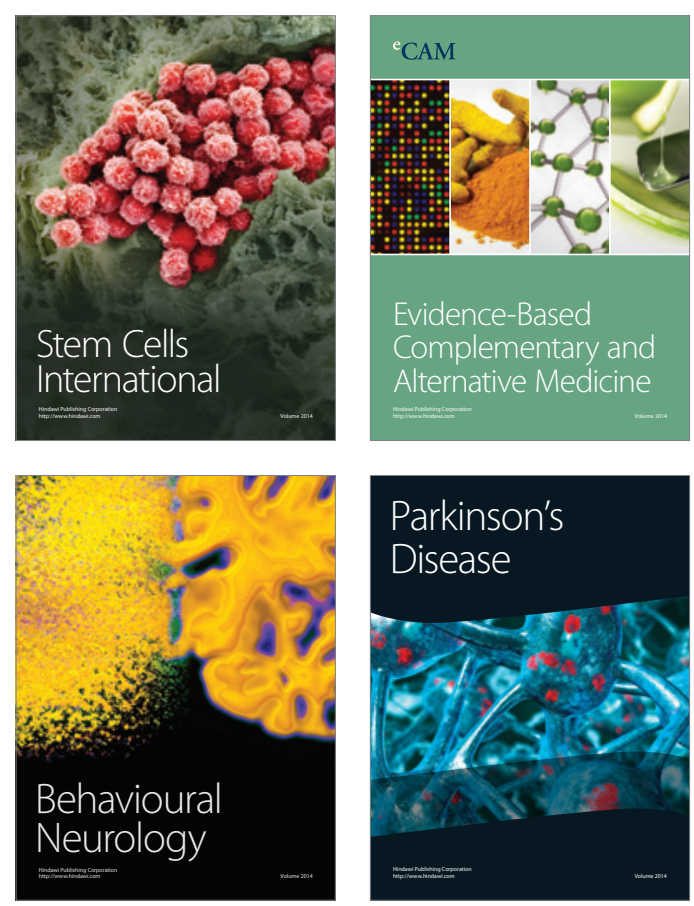

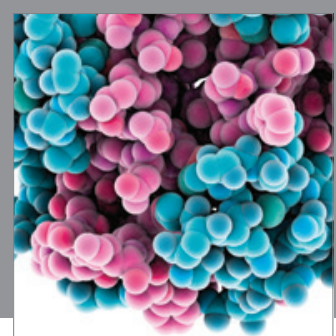

Journal of
Diabetes Research

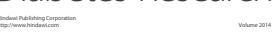

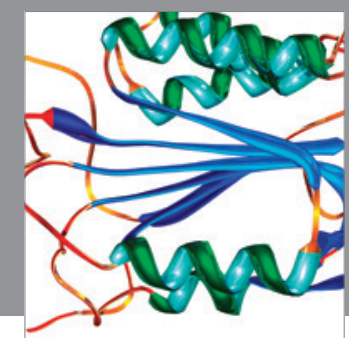

Disease Markers
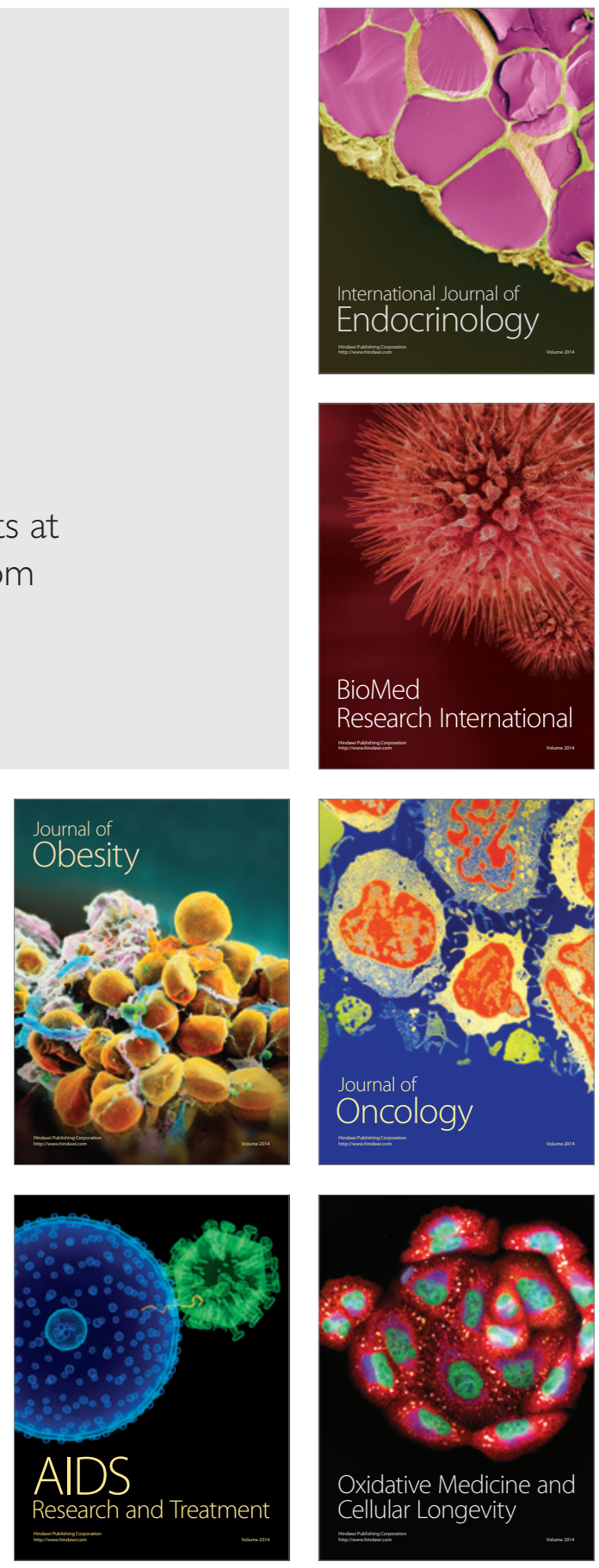